\title{
THE IMPACTS OF EXPERIENTIAL MARKETING ON THE CONSUMER BEHAVIOR IN RETAIL STORES: THE PROPOSAL OF A THEORETICAL MODEL
}

\author{
Amal Doulkaid and Lahoucine Berbou
}

Hassan 1st University, ENCG Settat, Morocco

\begin{abstract}
Due to the rising of personal incomes and living standards, consumers are more focused on their personal style and taste. Consumption patterns are also changed from the past "industrial economy," to " service economy," and now to "experiential economy." Therefore, in the experience economy we live through; marketing theorists and implementers are in search of unique and entertaining experiences to create customer dependence. In this context, strategies of marketing world has changed and developed to provide consumer experience rather than selling product and service. Experience is the main component of experiential marketing and it aims to make consumers respond, act actively to purchase and gain different feelings, different perceptions in consequence of their experiences. Its purpose is to appeal to the emotional senses of the customers and to influence their choice decision. The literature revue reveals that emotions constitute potent, pervasive, predictable, sometimes harmful and sometimes beneficial drivers of decision-making. Across different domains, important regularities appear in the mechanisms through which emotions influence judgments and choices. The purpose of this paper is to study the role of emotions and analyze the impacts of experiential marketing on the consumer behavior in retail stores in Morocco. Our research has theoretical and managerial interests. The theoretical one is a twofold interests: The first is revisiting the decision-making approaches by completing the cognitive dimension by an emotional one. The second interest is proposing and testing a model that relates the role of emotions and experience in the decision-making process. The managerial interest is enabling companies to identify the elements able to generate favorable emotional responses, which will influence the consumer behavior and their decision-making process.
\end{abstract}

Keywords : experiential marketing, emotions, decision making, consumer behavior, retail stores.

\section{Introduction}

Understanding consumers and their consumption experiences with products and services, with brands, in retail environments, is one of the core tasks of marketing. In recent years, companies are much interested in the creation and the production of experiences for their clients in their point of sales. They have understood the emergence of a third function of the point of sale: the recreational function.

Indeed, the store serves not only to buy products, it is also a source of multiple interactions for the individual in particular; interactions with products, contact personnel, and other clients. These can be a source of hedonistic gratification. (Mr. Filser, V. Garets, Paché 2001). The store is considered as a social place. Visiting the point of sale is in itself considered as relaxing activity, and source of value for the individual. That visit becomes more important than the products offered there (Filser, 2001).This strategic change in the stores is due to several developments in consumer behavior, consumption and retail trade: Firstly, it's worth noting that the competition has increased, the products have almost the same functional attributes. And then, consumers hardly make choices. Traditional marketing strategies based on price or quality are no longer sources of differentiation and are no longer a competitive advantage. Therefore, it has become essential for any business concerned about its survival and sustainability of differentiation over competitors and communicate a competitive advantage.

Researchers have shown that the only way to achieve differentiation is to focus on the consumer (Peppers and Rogers, 2004). Hence, companies have moved from traditional marketing based on the characteristics and functional attributes of the product to an experiential marketing consumer-focused, designed to create experiences for consumers (Williams, 2006). This type of marketing include relevance, novelty, surprise, learning and engagement (Schmitt, 1999; Poulsson and Kale (2000). Following the profound evolution of the theoretical status of the consumer in the marketing field, since 1980, consumption is no longer regarded as "final". Consumption 
is gradually disengaged from its utilitarian value. (Vézina 1999). She turned to reach a state of "post-modern" Firat \& Venkatesh (1993) Mr. B. Holbrook E. \& C. Hirschman (1993.

Besides being functional, the consumption can be symbolic in nature, hedonic and aesthetic. Therefore, consumer activities, far from seeking only to maximize utility, can be sources of emotions, pleasure, hedonic rewards, and for themselves (Holbrook \& Hirschman 1982).On the other hand, the modern consumer no longer seeks to maximize profit, he is no longer looking for functional attributes only. He is looking for sensitive experiments that can give him the interaction with products and services in the consumer system (Mafessoli 1990). He is then perceived as an emotional being. Then all the most work which focused on consumers and which are based on the traditional decision making process -information processing - had neglected the emotional dimension. The pioneer article of Holbrook \& Hirschman in 1982 highlighted the need to supplement or go beyond traditional analytical frameworks which postulate the rationality of the individual and its consumption. And this by the consideration of the experiential aspects of consumption. Later, several consumer behavior researchers have shown the limits of cognitive models and their ability to assess satisfaction and subsequent behavior (Bagozzi, 1997; Erevelles 1998; Ladhari, 2007; Phillips and Baumgartner, 2002; Smith and Bolton, 2002). For that reason and in response to the traditional models limits, Holbrook \& Hirschman (1982) suggest an alternative model: the research model of experiences that enriched the knowledge of consumer behavior.

This model introduces the importance of imagination, fun, entertainment and symbolism in individual consuming process. It does not replace the traditional behaviorist approach but complete it by adding the emotional dimension. Lofman (1991) summarized that in the following process: cognition-affect-behavior-satisfaction. Other authors proposed the ordered sequence complemented by thoughts sequence - Emotions-value, activities formalized by Holbrook and Hirschman 1986 (Nicosia, 1966. Engel et al, 1968; Howard and Sheth, 1969). Following the rise of experiential perspective, the concept of emotion occupies a more and more prominent in the research on consumer behavior. Emotions influence positively or negatively on consumer behavior and participate in the formation of satisfaction (Westbrook, Oliver 1991; Evrard, Aurier 1994).

\section{Theoretical framework}

\section{a. Experience}

The theme "experiential" took its origins in the pioneering article of Holbrook and Hirschman in 1982, the authors propose to enrich the traditional process information by filling out the experiential perspective. In other words, the consumer behavior requires understanding beyond mere information. The inclusion of additional features such as multi-sensory product characteristics, experiences, emotions, feelings, the time constraint in the pursuit of pleasure and the role of entertainment material in. These elements play a vital role in the process of choice and consumer decision.

According to Dominique Marc Bourgeon and Filser, the experience research model challenges the traditional hierarchy of components in the attitude to explain the decision of the consumer: it fits well in the current theoretical reflection that strives to qualify the assumption of a sequential process of forming the attitude massively resorting to verbal information. The traditional model has neglected other dimensions including hedonic. So it was to take into account of the phenomenological aspects of consumption, according to these authors, were not reducible to purely rational facets. Hence the emergence of a new trend: Experiential current that considers the consumer as a rational and emotional, looking for holistic experiences, fun and pleasure. Two currents influenced the consumer experience:

- The first current He focused on the consequences of the experience. That means on the content of the experience of the consumer and the impacts of experience on the consumer behavior (Holbrook and Hirschman, 1982 ; Filser, 2008).

- The second current: He was interested on the strategic part, which concerns the experience production as a source of differentiation of the company's offer (Pine and Gilmore, 1999).

Our research further focuses on the impacts of experiential approaches on the consumer behavior. So we will focus rather on the first current to specify a definition of the experience lived in the stores. Holbrook \& Hirschman (1982), define the experience as a subjective state of consciousness, accompanied by symbolic meanings, hedonic responses and aesthetic criteria. Filser (2002) defines the concept "experience" as the positive or negative consequences withdrawn from use of property or service, generating meaning for the subject who saw it. The experience can be seen as a process (Arnould, Price and Zinkhan 2002), which covers the entire living (Benavent, Evrard 2002) see in some cases, proof that the individual 
will retain the brand during his lifetime. As regards Sherry and al. (2001) experience is a product in a holistic sense. Punj and Stewart (1983), define the concept as an interaction "person", "object" and "situation", which is part of a temporality and a private space. This interaction is often accompanied by emotional meanings, based on the interaction with stimuli (Arnould \& Price,1993; Gentile, Spiller, Noci 2007; Grewal, Levy and Kumar, 2009); The consumer behavior experiential perspective highlights the importance of the recognition of the subjective nature of consumption. Holbrook \& Hirschman, 1982, believe that hedonic consumption is linked to emotional aspects of the experience of consumption or the use of the product. The following paragraph highlights the concept of emotions.

\section{b. Emotions}

Atkinson 1987 summarizes the definitions proposed by researchers in five components: a subjective reaction, internal bodily reactions, feelings or awareness of the advent of a positive or negative situation, facial or postural expression, a reaction relation to the presumed source of emotion.

Emotion is defined as a psychological state of arousal accompanied by cognitive aspects that depend on the specific context. Three important trends can be identified in the conceptualization of emotions, these include: $\S$ First stream: This current defines emotions based on the distinction between basic / complex emotion (Primary / Secondary). $\S$ The second trend: It distinguishes between negative emotions and positive emotions. § The third stream: It defines emotion as the emotional response, subjective, momentary and multidimensional in response to an exogenous factor to the individual, a context or a stimulus.

We focused on the third stream to define emotions as the set of emotional responses caused during the use of a product or consumer experiences when buying. It is a set of interrelated changes synchronized in response to a event / stimulus (Westbrook et Oliver 1991 ; Scherer 1987, 2001; Damasio, 2003; Niedental et al. 2004). Many theoris have tried to show the source of emotions:

- Cognitive appraisal theory

(Appraisal Theory) Arnould 1960, and many others (Lazarus, Mandler, Bagozzi, Gopinath, and Nyer 1999 etc ...) Arnold is the first founder of this theory, he started with "cognitive theory" in 1960, it advocates that the first step in the emotion is the assessment of the situation. Proponents of this theory defend the role of the cognitive component in the emotion. The emotions are not triggered by events as such but by the interpretation and appreciation of events.
Emotions are a comparison between a desirable goal and the degree of achievement of this goal.

•Emotional theory Zajonc 1980

This theory advocates the partial independence of emotional and cognitive systems. It argues that the essential emotion is excitement, arousal, not an evaluation. Emotions do not need cognitions to occur. In our research, we will focus rather on this last emotional theory.

c. The impacts of the store atmosphere on the consumer behavior:

There are two currents that explain the influence of the environment on the consumer behavior in the store. $\S$ The first current: The behaviorist current It argues the direct influence of the environment on the consumer behavior. $\S$ The second current: The psychologist current It interests firstly on the way an individual perceives, interprets and evaluates the situation and also on the action that this subjective situation - resulting from these processes - can impact the behavior. We favor the psychologist approach. Indeed, consumer experiences in a point of sale are accompanied by intense emotional experiences that precede the decision to purchase. The modeling of the consumption experience should emphasis the importance of the internal states, especially the emotional states of individuals. This will not prevent to keep the behaviorist approach, which defends the direct action of stimuli on behavior. Indeed, the existence of direct effects could also be helpful . The first attempts to model the influence of the atmosphere on the reactions of customers come from a part of the work of psychologists Mehrabian \& Russell (1974) and also research Kotler (1973-1974). Both frameworks have the same structure : the environmental stimuli cause internal responses in the individual responses that in turn influence customer behavior at the point of sale. These models are therefore off a completely objective approach to the situation and consider the study of the influence of the atmosphere on customer feedback through the integration of emotional and cognitive internal variables. Mehrabian \& Russel focus on affective reactions. Kotler emphasizes the need to also take into account the cognitive influence. Specifically, according to Mehrabian and Russel (1974), there are three emotional states likely to be influenced by the atmospheric variables ( These three emotional states are often listed under the name of PAD in the literature. They correspond to the following dimensions:

o Pleausre : pleasure, displeasure. This dimension reflects the degree of well-being of the individual;

o Arousal : stimulation, no stimulation. This feature reflects the degree of awakening and consumer activation. 
o Dominance : domination, submission. This dimension reflects the feeling of being free to act in the situation. These three dimensions can explain the variety of emotional reactions of the individual to the environment ( Mehrabian and Russell, 1974). After specifying the main stages in the consideration of situations in explaining buying behavior, it is important to define more precisely the notions situation ( stimulus), response ( body) and behavior in the model SOR as applied in marketing.

i. Stimuli:

Several researchers have agreed on the influence of the environment on consumer behavior and decision making process. These include:

$\S$ Kotler (1974) considers the atmosphere as a marketing tool. The quality of the business environment is perceived through the " main sensory channels of the atmosphere such as sight, hearing, smell and touch," corresponding to its major components (visual, auditory, olfactory and tactile ). Thus, for the author :

$\ddot{u}$ The atmosphere is apprehended by the sensory stimulation exclusively of individuals;

ü The influence of the atmosphere estconsidérée as necessarily positive, and in particular the probability of purchase .

$\S$ Hall (1966), proposed an integrated framework for analysis of the relationship that the subject establishes with its environment through its various meanings, linking basic sensory perceptions to the sensations and the emotional states that result.

$\S$ Baker (1986), fundamentally breaks with the sensory approach of Kotler. According to Baker, the store environment influences the behavior of individuals and their purchasing decision in the point of sale through three dimensions, namely; the environmental factors, design factors and social factors.

$\S$ According to Bitner (1992), the relationship between the environment of the point of sale and the consumer behavior should take into account a holistic perception of the environment by individuals (ambient conditions, spatial organization and functionality, signs, symbols and artifacts).

$\S$ Carbone and Haeckel (1994) distinguished two components of the atmosphere that may influence the behavior of the individual within the point of sale:

ü Social component : The consumer interaction with employees and with other consumers. Price, Arnould and
Tierney (1995) found that positive perceptions of relational context (social environment) impact positive affect consumer satisfaction and long-term. Bitner (1990) shows that positive affect results from contact between the consumer and the employee.

ü Physical Component : Applies to tangible aspects of the service involves the five senses.

We believe that all these approaches are complementary rather than antagonistic and their combination is desirable to better understand the relationship between the individual and his environment.

ii. Organism:

According to the model of Mehrabian and Russell, who is part of a psychological approach, the environment does not exert a direct influence on the behavior of individuals. This action is mediated, it goes through the internal responses of the individual, which in turn will have an effect on the behavior. The hypothesis of this mediating effect is the specificity of S -O -R models vs. The behaviorist approach for which the environment directly affects the behavior of individuals. Since we adopted the psychological approach.

We consider our work affective reactions as mediating variables between stimuli from the point of sale and the behavior of the individual and his purchase decision.

iii. Reactions:

As regards the theories that help to explain the causal influence of the emotions of the individual over his behavior and purchasing decisions, theoretical perspectives have been proposed. It is possible to divide them into two groups: static evaluation theories of affect regulation and dynamic theories of affect (Andrade 2005).

\section{$\S$ First theory:}

According to this theory, affective reactions precede cognitive reactions. Moreover, they are the result of the emotions aroused by the environment of the point of sale. Which will subsequently influence the judgment and therefore the behavior of the individual and his purchase decision.

Emotional reactions $\rightarrow$ information processing $\rightarrow$ Judgment Behavior

This theory joins the current claims that emotions can be used as a source of information (as Affect information), they can be accessed by the consumer before issuing an evaluative judgment. 


\section{$\S$ Second theory:}

Difference between two emotional reactions in two points in time plays a major role in guiding the affective behavior (how he feels now and how it might feel in the future as a result of behavioral activity). Several psychological scientists recognize the role and recognize that emotions are what drive most significant decisions in life (e.g., Ekman 2007, Frijda 1988, Gilbert 2006, Keltner et al. 2014, Keltner \& Lerner 2010, Lazarus 1991, Loewenstein et al. 2001, Scherer \& Ekman 1984).

d. Proposal for a model to explain the causal relationship between experience, emotion, and the consumer behavior in a store.

The theoretical study of the shopping experience in retail stores has highlighted the important role of consumer affective states. This justified the choice of an S -O - R model as the basic model to develop an explanatory model and linking experience, emotion, and the consumer behavior. The role of consumer's emotions is central.
Research by Donovan and Rossiter (1982) were the first to point out that the influence of the environment on consumer behavior was exercised through the effect of the environment on his emotional state. Emotional response, indeed, is a mediating variable between perceived the atmosphere of the store and the behavior of individuals. The central hypothesis of the SOR model is that the environmental variables exert their influence on the behavior of the individual through his emotional states in a store. Although we have passed the psychological approach, we do not reject any of the same behaviorist approach, which defends the direct action of stimuli on behavioral reactions. In addition, the behavior will include the variables "time spent in the store", "and the "amount spent ".

In our research model, we will take into account three kinds of moderating variables : Pressure time, Socio demographic variables and individual variables and finally attitudinal variables. To operationalize the final research model, assumptions will be fixed and then we will proceed to the empirical validation. This last is based on the choice of the point of sale, the sampling method and the various measures of the study variables.

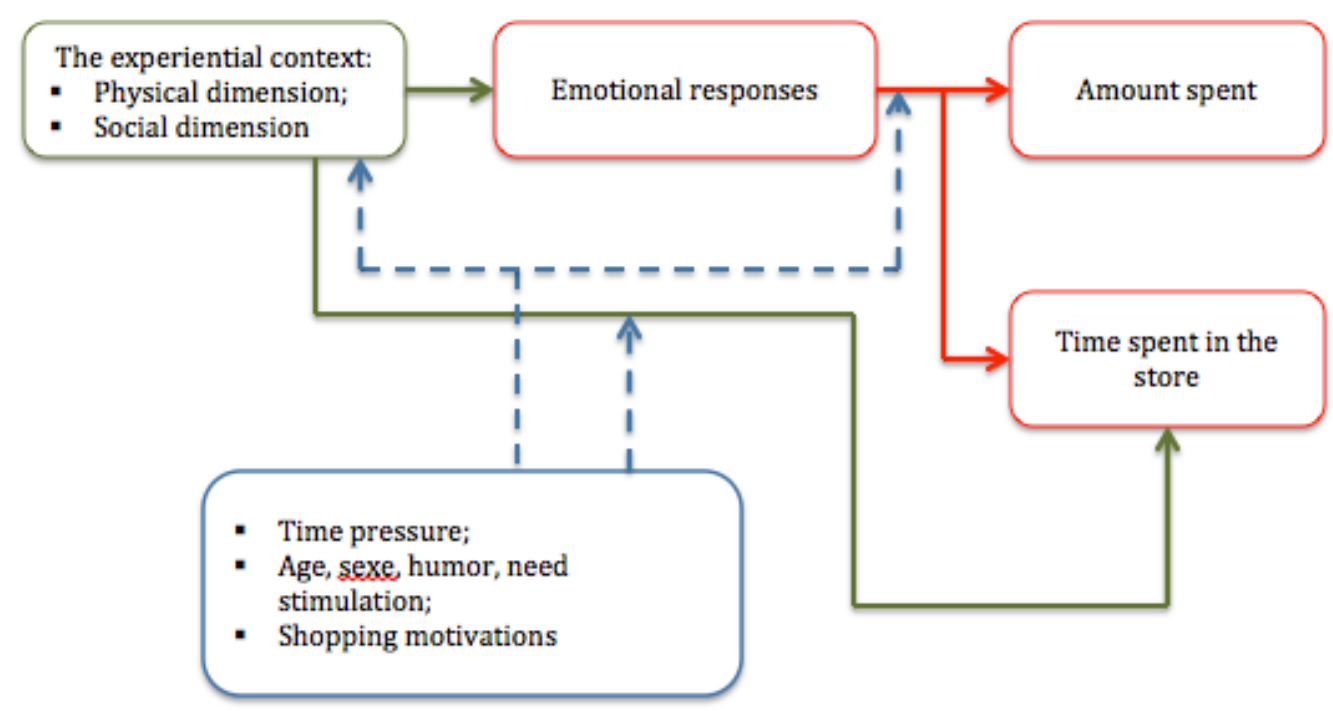

Figure 1: Theoretical model

Future research will have for main objectives to study empirically the impact of experiences on behavior while including different variables that may moderate the relationship, study and analyze the role of emotions in the process of choice and decision-making and finally the development of measuring instruments capable of measuring the impact of emotions on consumer behavior and decision- making. From an operational point of view, this research can only help to better understand, explain and predict consumer behavior, to establish new types of consumers, to explain market segmentation based on emotional reactions experienced by individuals and to guide practitioners in their choice of marketing policies.

\section{References}

Le marketing de la production de l'expérience: Statut théorique et implication managériales. Marc Filser. Décisions Marketing 2002 Expériences et magasinage et appropriation des espaces commerciaux: Management et Avenir 2011 
Contribution à la conceptualisation de l'expérience de consommation: Recherche et applications en marketing 2012

Luxury brand marketing- the experience is everything: Journal of brand management 2009

Experiential marketing Vs traditional marketing: creating a rational and emotional liaison with consumers- The Romanian Economic Journal 2008

Consuming experiences, Caru et Cova 2007

The impact of experiential consumption cognitions and emotions on behavioral intentions: Journal of Services Marketing 2008

Ability of experience design elements to elicit emotions and loyalty behaviors: Decision Sciences 2004

The role of positive emotions in experiential decisions: International Journal of Research in Marketing 2007

Holistic framework for conceptualizing customer experiences in retail environment: International Journal of Design 2013

Experiential marketing: Emerging issues and suggestions; International Journal of Advances in Management and Economics 2014

Experiential marketing: An insight into the mind of the consumer; Asian Journal of Business and Management Sciences, How experiential marketing can be used to build brands; Innovative Marketing, volume 4, 2008

Emotions that influence purchase decisions and their electronic processing, 2009

Emotion and strategic decision-making behavior: developing a theoretical model; International Jounral of Business and Social Science, volume 3, 2012

On emotion specificity in decision making: Why feeling is for doing; Judgment and Decisions Making, Volume 3, 2008

Emotion and Decision Making, Reviews in advance 2014

Experiential shopping at the Mall: influence on consumer behavior; China-USA Business Review, Volume 10, 2011

The experiential Aspects of Consumption: Consumer Fantasies, Feelings and Fun. Holbrook, Hirshman. The journal of Consumer Research, 1982

Experiential product attributes and preferences for new products: The role of processing fluency. The journal of Business Research 2014

From experiential psychology to consumer experience. Journal of Consumer Psychology, 2015

Epistemological view of consumer experiences. International Journal of Hospitality Management, 2011

Emotion and decision-making: affect-driven belief systems in anxiety and depression. Trends in Cognitive Science, 2012

Shaping e-retailer's website personality: The importance of experiential marketing. Journal of Retailing and Consumer Services, 2013

Recreation demand of consumer with experiential Marketing in Festival. Procedia social and behavioral sciences, 2011
Experiential Marketing and Vacation Experience, Procedia social and behavioral sciences, 2014

Le rôle de l'appropriation dans l'expérience de consommation alimentaire. Une analyse de blogs, 2009

A Behavioral Decision Theoretic Perspective on Hedonic and Utilitarian Choice, Frontiers of Research on Consumer Motives, Goals, and Desires, 2004

Feelings First: The Role of Positive Emotions in Consumer Decision Making For Experiential Products. The Journal of Consumer Research, 2005

L'Affectif dans les comportements d'Achat et de Consommation ; Marc Filser, Christian Derbaix, 2012

Measuring emotions in customer experiences in retail store environments, 2009

Describing and Measuring Emotional Response to Shopping Experience. The Journal of Business Research, 2000

Customer Experience Creation: Determinants, Dynamics and Management Strategies. Journal of Retailing, 2009

Measuring Emotions in a Consumer decision-making Context - Approaching or Avoiding, 2008

How Does the Retail Environment Influence Shoppers' Emotional Experience? Evidence from Two Retail Settings, 2005, 2006

Entre recherche et production d'expérience dans les environnements commerçants : L’Expérience vécue

Les émotions ressenties dans un point de vente, 2004

La prédisposition à la recherche d'expériences comme caractéristique individuelle : un élément de la complémentarité entre théorie classique et approche expérientielle, 2008

Le comportement du consommateur sur un site marchand est-il fondamentalement différent de son comportement en magasin ? Proposition d'un cadre d'appréhension de ses spécificités. Recherche et Application en Marketing Vol 16, $\mathrm{N}^{\circ} 3 / 2001$

Le consommateur et le déplacement au point de vente. 5ème colloque Etienne, 2002

Contribution à la conceptualisation de l'expérience de consommation : émergence des dimensions de l'expérience au travers de récits de vie. Recherche et Applications en Marketing, Vol 27, N³/2012

Effet de la valeur perçue de magasinage sur le comportement du consommateur: Cas d'un point de vente spécialisé. La Revue des Sciences de Gestion, Direction et Gestion n 237-238 - Marketing, 2009

Emotions et comportement du consommateur, RAM, Vol $13, \mathrm{~N}^{\circ} 1 / 1998$

La mobilité du consommateur en magasin : une etude exploratoire de l'influence de l'aménagement spatial. 